\title{
Study of Viral Diarrhoea and Associated Risk Factors Among Under Five Years Old Children in Dhulikhel Hospital, Kathmandu University Hospital
}

\author{
Anish Joshi ${ }^{1 *}$, Ranendra Prakash Bahadur Shrestha ${ }^{1}$
}

BACKGROUND: Diarrhoea is a major health problem among children. It remains a major cause of childhood morbidity and mortality worldwide, with particularly high morbidity in children younger than 5 years of age. The objective of this study is to determine the frequency and associated risk factors of viral diarrhoea in children less than 5 years of age at Dhulikhel Hospital, Kathmandu University Hospital, Nepal and also to study the clinical presentation and the common causes of acute childhood diarrhoea.

METHODS: This is a hospital based, prospective, non-interventional study conducted in Dhulikhel hospital. A total of 100 cases attending Dhulikhel hospital between 1st December 2011 to 31st March 2012 , presented with acute onset of diarrhoea were enrolled in the study. During the study period the parents were asked to respond to questionnaires regarding their family size, educational status and knowledge of Oral Rehydration Solution (ORS), their water source and sanitation, personal hygiene and food habit. The children were examined, assessed for dehydration and anthropometry was also taken. The fresh stool specimens were analysed in the hospital laboratory in order to look for the common pathogens. All the statistical analysis was done using both descriptive and inferential ( $\chi^{2}$ test) statistics with the help of SPSS 20 software.

RESULTS: Out of 100 children studied 69\% were males and $31 \%$ females. Majority of the study population were below 24 months of age $(77 \%)$. Majority were classified as no dehydration $(75 \%)$ as per WHO guidelines for assessment of dehydration. The main source of drinking water in the family was tap water $(65 \%)$, 44\% didn't used any method for water purification and $26 \%$ had no habits of hand washing in the family, $89 \%$ of the mothers had a good knowledge of ORS. Majority had no history of fever (64\%). 37\% of cases needed hospital admission among which 7 cases needed PICU care. Test was positive for Rotavirus in significant number of cases (66\%) followed by Adenovirus (13\%).

CONCLUSIONS: Incidence of Acute diarrhoea is highest below 24 months of age. As the age increases the incidence decreases. Lack of safe drinking water, poor sanitation and poor living conditions are associated risk factors for childhood diarrhoea. Viral diarrhoea is still the most common cause of childhood diarrhoea. Most children are not dehydrated and can be managed using ORS at home or in primary health care centres. We expect that results of the study would be useful initiation of vaccine requirements in a developing country like Nepal.

KEY WORDS: Children, diarrhoea, dehydration, rotavirus

(C) 2015 Nepalese Association for Clinical Chemistry Introduction

Diarrhoea is a clinical syndrome of diverse etiology, associated with passage of more than three loose stools in a 24 hours period and often accompanied by other clinical sign and symptoms including vomiting, fever, dehydration and electrolyte disturbances [1]. Diarrhoea is a major health problem among children. In addition, it remains a major cause of childhood morbidity and mortality worldwide [2].

Diarrheal diseases caused by bacteria, parasites or viruses continues to be an important cause of morbidity and mortality among young children in developing countries [3]. The highest mortality from diarrhea is in children under the age of five, highlighting an urgent need for focused interventions to prevent diarrhoea disease in this age group [4]. Five million children under the age of 2 years die from diarrheal disease in developing countries each year and rotavirus infections account for about $20 \%$ of these deaths [5].

In Nepal, around 13,000 Nepalese children under five years die each year from sanitation, hygiene and water related diseases [6]. Though precise data on childhood mortality associated with diarrheal diseases in Nepal is not available, it has been estimated that approximately $25 \%$ of child death are associated with diarrheal diseases, particularly acute diarrhea [7]. This study aims to analyze the incidence of diarrheal diseases, water supply and sanitation status, and the type of interventions required to reduce morbidity and

${ }^{1}$ Department of Pediatrics, Dhulikhel Hospital, Kathmandu University Hospital, Nepal 
mortality due to diarrheal diseases in Nepal. Since, Dhulikhel hospital is the only tertiary level health care centre in this area, majority of the children of the vulnerable section of the population suffering from diarrhoea and other illness are likely to attain this hospital. Diarrhoea is the second commonest cause of infection related disease among under 5 children admitted in Dhulikhel hospital after pneumonia. High risk groups and mothers with children under 5 years old should be aware of these risk factors in order to prevent their children's disease. The primary objective of this study was to assess the frequency and clinical characteristics of childhood diarrhoea, diarrhoea severe enough to bring a child to medical attention. We expect that results of the study would be useful initiation of vaccine requirements in a developing country like Nepal.

\section{Methods}

This study hospital-based, prospective, noninterventional study was carried out in Department of Pediatrics, Dhulikhel Hospital/Kathmandu University Hospital from $1^{\text {st }}$ December 2011 to $31^{\text {st }}$ March 2012, over 4 months period. A total of 100 cases were analyzed.

\section{DATA COLLECTION}

During the study period the parents of the selected cases were asked to respond to questionnaires to record their children's age, sex, family size, educational status, mother's employment and knowledge of ORS, clinical history including duration of illness, fever, antibiotics used prior to attending the hospital, source of drinking water and sanitation, personal hygiene, food habit, duration of exclusive breast feeding and immunization status. Sociodemographic condition, anthropometry, clinical status, degree of dehydration, duration of hospital stay and treatment outcome was also recorded. The questionnaires were pretested in 20 diarrheal cases who attended Dhulikhel hospital prior to the study. The definition of diarrhoea, dehydration status and its management was assessed and classified according to the guidelines of the World Health Organization (WHO), which is followed in the Integrated Management of Childhood Illness (IMCI) training.

Mild, moderate and severe fever was defined as a rectal temperature of $37.7^{\circ} \mathrm{C}-38.5^{\circ} \mathrm{C}, 38.6^{\circ} \mathrm{C}$ $-39.5^{\circ} \mathrm{C}$ and $>39.5^{\circ} \mathrm{C}$, respectively.

Personal hygiene was best represented by the mother's reported hand washing habits. Mothers were asked to list at what times during the day she typically washes her hands, after defecation, prior to preparing food, and prior to eating.

Treatment of water used for drinking or cooking was assessed by asking respondents what methods they knew about for cleaning water, and in conjunction, which of those methods they used. Whether or not the mother prepared ORS (rice water, coconut milk, watery soup) at home the last time her child had diarrhoea was used as the indicator for knowledge of ORS.

If an organism was identified from the stool sample, the child was classified as "infected" with that organism. "Undiagnosed diarrhoea" included any episode in which a studied pathogen was undetected.

\section{SPECIMEN ANALYSIS}

All the 100 stool specimen was analysed in the hospital laboratory. Single faecal specimen was collected from each patient, freshly passed stool samples were collected in clean plastic containers. All the samples were examined within 2 hours of collection. The specimen was subjected to naked eye examination for consistency, colour, and atypical components, then sample was examined for leucocytes, macrophages, RBCs, mucus, reducing substance and fat droplets.

Following the manufacturer's instructions the CerTest Rota-Adeno Card (Biotec, Zaragoza, Spain) an immunochromatographic test for rotavirus and adenovirus detection in stool specimens was performed. The sensitivity for rotavirus and adenovirus detection of this test system is $100 \%$ and $90 \%$ respectively, and the specificity for rotavirus and adenovirus detection of this test system is $99 \%$ and $100 \%$, respectively $[8,9]$. All the stool samples were collected in clean containers and the assay done right after collection. The samples were stored in the refrigerator $\left(2-4^{\circ} \mathrm{C}\right)$ for 1 day if the tests were to be conducted the next day. The samples were brought to room temperature before the tests.

\section{ETHICAL ISSUE}

The research proposal was submitted to the Ethical Review Board of Kathmandu University School of Medical Sciences for approval. A written informed consent from parents or guardians of the enrolled child was taken prior to participation and stool collection for the study.

For the research purpose ELISA kits used for the detection of rotavirus and adenovirus were provided by Medical University of Innsbruck, 
Austria, Department of Microbiology. No financial burden was incurred to patient's expense, except for routine stool examination and routine charges as per hospital policy.

Inclusion criteria: Children under 5 years presented with acute onset of diarrhoea with or without nausea and vomiting attending in outpatient, emergency and those admitted in inpatient department were enrolled in the study with purposive sampling technique.

Exclusion criteria: Children with dysentery, newborns less than 28 days, children with persisting diarrhoea more than 14 days and children with other associated chronic disease were excluded.

Statistical analysis: Data was entered and analysed using SPSS (Statistical Package for Social Scientists) version 20. Data analysis was done using both descriptive (mean and percentage) and inferential ( $\chi^{2}$ test) statistics. Statistical test was considered significant at 0.05 level of confidence. Descriptive statistics was used to describe the incidence of the disease. Inferential statistics was used to describe the risk factors.

\section{Results}

A total of 100 cases of under 5 years old children attending Dhulikhel hospital between $1^{\text {st }}$ December 2011 to $31^{\text {st }}$ March 2012 fulfilling the inclusion criteria and whose parents gave consent to participate in the study were enrolled and studied.

Figure 1 shows majority of the study population were in the age group of 1 month to 12 months (48\%). Children less than 24 months occupied
$77 \%$ of the study population. The mean age was 17.6 months (S.D \pm 14.4 months). Out of 100 children studied $69 \%$ were males and $31 \%$ were females.

The majority of stool samples tested positive for rotavirus (66\%), and adenovirus (13\%) [Table $1]$.

Table 1. Frequency of infected cases detected

\begin{tabular}{lcc}
\hline Infected by & $\mathrm{N}$ & $\mathbf{\%}$ \\
\hline Rotavirus only & 56 & 56.0 \\
Adenovirus only & 3 & 3.0 \\
Both & 10 & 10.0 \\
None & 31 & 31.0 \\
Total & 100 & 100.0 \\
\hline
\end{tabular}

More than $78 \%$ (52 cases) of rotavirus positive cases were below 24 months of age, similarly more than 69\% (9 cases) of adenovirus positive cases were below 24 months of age. The mean age of rotavirus positive case and adenovirus positive case was 16.3 months and 19.7 months respectively.

The majority of children had a family size of 3-6 members (77\%), the mean number of members in the family was 5.4 members $(\mathrm{S} . \mathrm{D} \pm 2.3$ members).

The immunization status for their age according to Expanded Programme on Immunization (EPI) was completed in all the children $(100 \%)$ enrolled in the study and all children (100\%) had history of breast feeding. The mean duration of exclusive breast feeding was 3.77 months (S.D \pm 1.4 months). The prevalence of diarrhoea was found more in children who had weaning before 4 months of age (46\%), followed by weaning between 4-6 months (39\%) and weaning after 6 months (15\%).

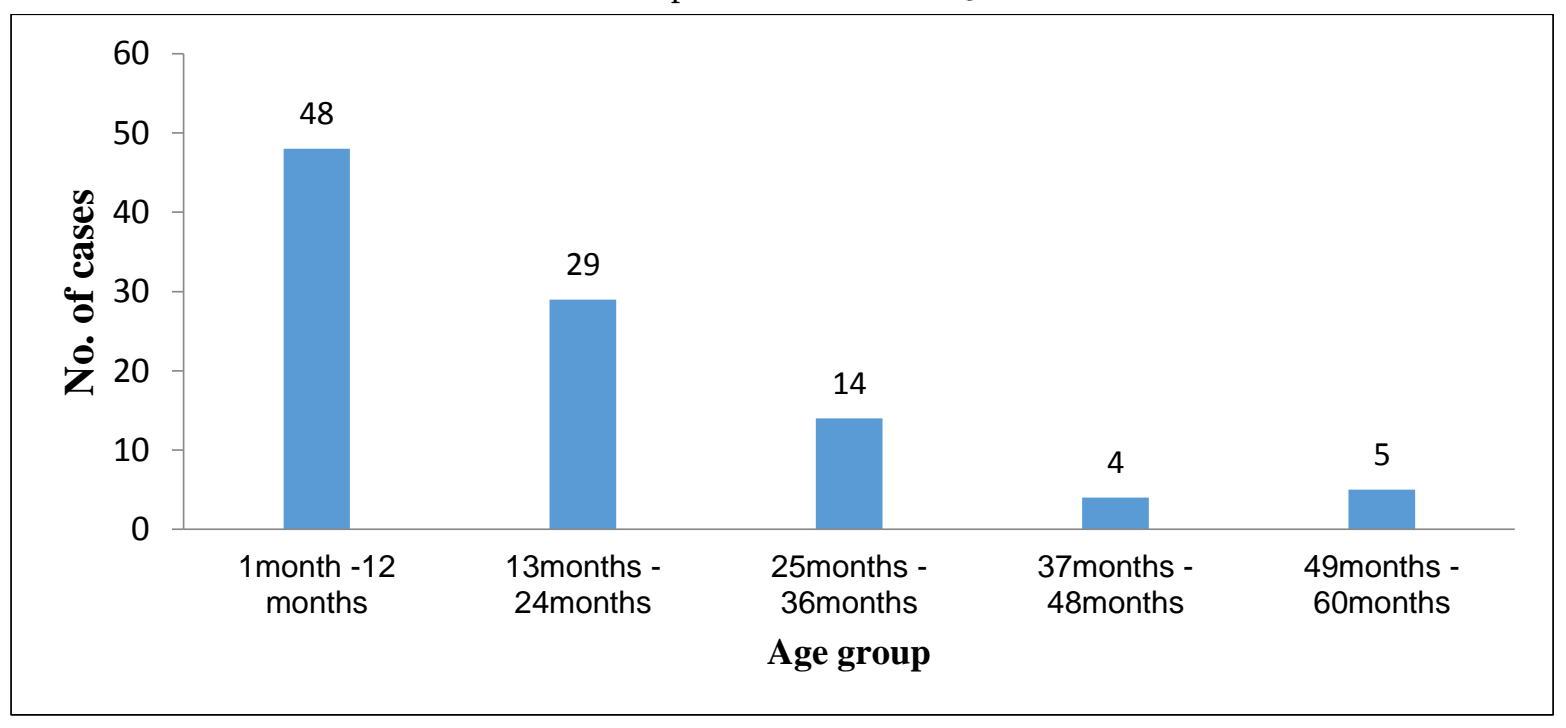

Figure 1. Distribution of study population in different age group. 
Table 2. Relation between infected cases with age

\begin{tabular}{lccc}
\multicolumn{4}{c}{ group } \\
\hline Infection with & $\begin{array}{c}\leq 24 \\
\text { months }\end{array}$ & $\begin{array}{c}>24 \\
\text { months }\end{array}$ & $\mathbf{p}$ \\
\hline $\begin{array}{l}\text { Rotavirus } \\
\text { (n=66) }\end{array}$ & $52(78.8 \%)$ & $14(21.2 \%)$ & 0.7 \\
$\begin{array}{l}\text { Adenovirus } \\
(\mathbf{n}=13)\end{array}$ & $9(69.2 \%)$ & $4(30.8 \%)$ & 0.4 \\
\hline
\end{tabular}

Seventy seven percent of the family had well maintained toilets in the family whereas 23\% used public toilets or relied on open defecations. Only $49 \%$ of the children were dewormed in last 6 months. $89 \%$ of the mothers had a good knowledge of ORS.

Seventy four percent of the family had habits of hand washing (53\% with soap and $21 \%$ without soap), whereas $26 \%$ had no habits of hand washing at all. The lack of clean water and proper technique of hand washing may contribute to the large number of diarrheal cases seen in hand washing group.

The main source of drinking water in family attending Dhulikhel hospital was tap water $(65 \%)$, followed by irrigation water $(17 \%)$, pond water $(10 \%)$ and underground water $(8 \%)$. Infected cases were found more in family where tap water was the main source of drinking water (rotavirus only 34, adenovirus only 3 and both 6) [Table 3].

The majority of the family (44\%) didn't used any method for water purification, whereas $38 \%$ used boiled water, $14 \%$ used filter water and $4 \%$ used some kind of disinfection method to purify drinking water. Infected cases were seen more in the family where no method for water purification was used (rotavirus only 22, adenovirus only 0 and both 6) [Table 4].
The mean duration of illness prior presentation to hospital was $3.2 \pm 1.5$ days.

Ninety seven percent of rotavirus positive cases had duration of illness of less than 6 days with the maximum of 9 days in 1 case, whereas all the adenovirus positive cases had duration of illness of less than 6 days with the maximum of 6 days in 1 case. The mean duration of illness of rotavirus and adenovirus positive cases prior presenting to the hospital was 3.2 days and 2.9 days, respectively.

Majority had no history of fever (64\%), 27\% had mild fever followed by $7 \%$ with moderate fever and $2 \%$ had severe grade of fever. Antibiotics were used in $29 \%$ of children prior to presentation. More than $77 \%$ (28 cases) of children having history of fever were below 24 months of age.

Comparing between the infected cases with history of fever, out of the 66 rotavirus positive cases more than $62 \%$ ( 41 cases) had no history of fever $(p=0.5)$, whereas out of the 13 adenovirus positive cases more than 69\% (9 cases) had history of fever which was statistically significant $(p=0.01)$ [Table 5].

Among all the 100 children assessed majority were classified as no dehydration (75\%), 20\% were classified as some dehydration and $5 \%$ as severe dehydration according to the WHO classification. Eighty percent $(20$ cases $)$ of children having some form of dehydration was found to be below 24 months of age. The incidence of dehydration was seen more in the age group of 1 month to 12 months (56\%). The mean age of some dehydration was 14.8 months, whereas the mean age for severe dehydration was 17 months.

Table 3: Frequency of study population by their source of drinking water

\begin{tabular}{lllllll}
\hline Source of water & $\mathbf{N}$ & Percent & Rotavirus only & Adenovirus only & Both & None \\
\hline Tap water & 65 & 65.0 & 34 & 3 & 6 & 22 \\
Irrigation water & 17 & 17.0 & 10 & 0 & 2 & 5 \\
Pond water & 10 & 10.0 & 7 & 0 & 0 & 3 \\
Underground water & 8 & 8.0 & 5 & 0 & 2 & 1 \\
Total & 100 & 100.0 & 56 & 3 & 10 & 31 \\
\hline
\end{tabular}

Table 4 Frequency of study population by their mode of water purification

\begin{tabular}{|c|c|c|c|c|c|c|}
\hline $\begin{array}{l}\text { Mode of water } \\
\text { purification }\end{array}$ & $\mathrm{N}$ & Percent & Rotavirus only & $\begin{array}{l}\text { Adenovirus } \\
\text { only }\end{array}$ & Both & None \\
\hline None & 44 & 44.0 & 22 & 0 & 6 & 16 \\
\hline Boiled water & 38 & 38.0 & 20 & 2 & 3 & 13 \\
\hline Filter water & 14 & 14.0 & 11 & 0 & 1 & 2 \\
\hline Disinfection & 4 & 4.0 & 3 & 1 & 0 & 0 \\
\hline Total & 100 & 100.0 & 56 & 3 & 10 & 31 \\
\hline
\end{tabular}


Comparing the infected cases with clinical signs of dehydration, more than $77 \%$ (51 cases) of rotavirus positive cases had no signs of dehydration, similarly more than $84 \%$ (11 cases) of adenovirus positive cases had no signs of dehydration.

Table 5. Relation between infected cases with history of fever

\begin{tabular}{lccc}
\hline Infection with & Yes & No & p \\
\hline $\begin{array}{l}\text { Rotavirus } \\
(\mathbf{n}=66)\end{array}$ & $25(37.9 \%)$ & $41(62.1 \%)$ & 0.5 \\
$\begin{array}{l}\text { Adenovirus } \\
(\mathbf{n}=13)\end{array}$ & $9(69.2 \%)$ & $4(30.8 \%)$ & 0.01 \\
\hline
\end{tabular}

$37 \%$ of cases needed hospital admission among which 7 cases needed PICU care. There were no mortality due to diarrhoea within the study period. The mean hospital stay was $1.1 \pm 1.7$ days. Comparing between the hospital admitted and infected cases, among the 66 rotavirus positive cases $36.4 \%$ (24 cases) needed hospital admission and among 13 adenovirus positive cases $46.2 \%$ (6 cases) needed hospital admission. More than $90 \%$ (60 cases) of rotavirus positive cases had the hospital stay of less than 3 days with the maximum of 9 days in 1 case, whereas all the adenovirus positive cases had the hospital stay of less than 3 days with the maximum of 3 days in 3 cases. The mean duration of hospital stay for rotavirus and adenovirus positive cases were 1.7 days and 1.5 days respectively.

There was no statistical significant correlation found between infected cases with reducing substance, WBC, RBC or mucus in stool investigation [Table 6]

\section{Discussion}

Children under 5 years presented with acute onset of diarrhoea with or without nausea and vomiting seen in outpatient, emergency and those admitted in inpatient paediatric department of Dhulikhel hospital during the study period were classified as no dehydration, some dehydration and severe dehydration according to WHO guidelines for assessment of dehydration.

Incidence of diarrhoea was more in male (69\%),
It might be the reflection of the fact that there is slight male predominance $(55 \%$ male vs. $45 \%$ female) in under five children in Nepal [10]. Since this study was a hospital based study, the culture of male preference may also have played some role for possible increase number of hospital visits for a male child in Dhulikhel hospital. This result was also supported by a similar study of diarrhoea done among children in eastern Nepal, where incidence of diarrhoea was seen more in male children (67.5\%) [11]. Although, male children were seen to suffer more from diarrhoea from other studies from Bangladesh, this difference in sex was not statistically significant $(P=0.5) \quad[12]$. The explanation to this male predominance remains unclear, and this difference bears no statistical significance.

In this study the highest numbers of diarrheal cases were found in children less than 12 months (48\%), followed by 13 to 24 months age group $(29 \%)$, and the number of diarrheal cases decreased thereafter. In a similar study done in Kathmandu valley by RajKarnikar et al, the number of episodes seeking treatment for diarrhoea increased from birth to 5 months old, peaked at 6 to 11 months old, and decreased over the next two successive age categories (i.e., 12 to 23 and 24 to 59 months) [13]. In a similar study of diarrhoea done among children in eastern Nepal, majority (70.9\%) of diarrhoea cases were observed in patients between 6 months and 2 years of age [11]. The same picture of age predisposition was observed in some studies from Bangladesh [14, 15] and India [16], similarly also from studies done among children in America [17].

In this study all the children (100\%) had history of breast feeding. The prevalence of diarrhoea was found more in children who had weaning before 4 months of age (46\%), followed by weaning between 4-6 months (39\%) and weaning after 6 months (15\%). The number of diarrheal cases decreased as the period of exclusive breast feeding increased. Exclusive breast-feeding for the first 6 months of life is

Table 6: Correlation between infected cases with reducing substance, mucus, WBC and RBC in stool.

\begin{tabular}{lcccccc}
\hline Parameters & $\begin{array}{c}\text { Rotavirus (+) } \\
\mathbf{n}=\mathbf{6 6}\end{array}$ & $\begin{array}{c}\text { Rotavirus (-) } \\
\mathbf{n}=\mathbf{3 4}\end{array}$ & $\mathbf{p}$ & $\begin{array}{c}\text { Adenovirus (+) } \\
\mathbf{n}=\mathbf{1 3}\end{array}$ & $\begin{array}{c}\text { Adenovirus (-) } \\
\mathbf{n}=\mathbf{8 7}\end{array}$ & $\mathbf{p}$ \\
\hline Reducing & $38(63.3 \%)$ & $22(36.7 \%)$ & 0.4 & $5(8.3 \%)$ & $55(91.7 \%)$ & 0.08 \\
substance & $27(64.3 \%)$ & $15(35.7 \%)$ & 0.7 & $6(14.3 \%)$ & $36(85.7 \%)$ & 0.7 \\
Mucus & $14(77.8 \%)$ & $4(22.2 \%)$ & 0.2 & $4(22.2 \%)$ & $14(77.8 \%)$ & 0.2 \\
RBC & $11(73.3 \%)$ & $4(26.7 \%)$ & 0.5 & $6(40.0 \%)$ & $9(60.0 \%)$ & 0.004 \\
WBC & & & & & & \\
\hline
\end{tabular}


widely regarded as one of the most effective interventions to reduce the risk of premature childhood mortality and the potential to prevent $13 \%$ of all deaths of children $<5 \mathrm{yr}$ of age [18]. Breast feeding is a traditional and universal practice in Nepal [19].

The Family Health Survey in Nepal (1996) reported Housing conditions were poor and overcrowded in most cases [20]. The survey data showed that 37\% of households had 3-4 persons in a room. A study by Stanton \& Clemens (1987) in Dhaka, Bangladesh, showed that low family income and living in a one-room house were statistically associated with increased diarrhoea attacks [21]. In this study, the majority of children presented had a family size of 3-6 members $(77 \%)$. No correlation of crowding with diarrhoea was seen in this study.

Eighty nine percent of the mothers had a good knowledge of ORS. Majority of the children attending Dhulikhel hospital belong to low to middle income families residing in the peripheral regions of the capital city and adjacent districts. Since this institute is the only tertiary level health care centre in this area, majority of the children of the vulnerable section of the population suffering from diarrhoea and other illnesses are likely to attend this hospital. Diarrheal diseases are still a major challenge in Nepal because of inadequate safe water supply, poor sanitation and living conditions. Interventions such as piped water supply, sanitation, hand washing with soap and hygiene education are considered to be effective tools to control diarrheal diseases. Improvements in water and sanitation facilities are believed to reduce the transmission and ingestion of faecal-oral pathogens, particularly the major infectious agents of diarrhoea (Esrey $\&$ Habicht 1986). In this study, $23 \%$ still used public toilets or still relied on open defecations. $26 \%$ had no habits of hand washing in the family. Main source of water in family was tap water (65\%). Majority of the family didn't use any method for water purification (44\%). Contaminated drinking water may be one of the reasons why we found high prevalence of diarrheal cases in families using tap water, whereas the less chance of contamination in underground water may be the reason we found minority (8\%) of children who used underground water as the main source of drinking water. The water samples collected from the water supply system of the Kathmandu valley showed one or more bacterial species $(75 \%$ i.e. 43 out of 57 samples tested) out of which
$51 \%$ were E. coli (22 out of 43 ). The authors concluded that contamination of the drinking water was the reason for the diarrhoea incidence [22].

Although most children with gastroenteritis do not require admission to hospital, many are treated as inpatients each year. Once admitted they often remain in the hospital for several days. This is a significant burden for the health services [23]. Admission also carries a serious risk of spread to other children in the hospital, some of whom may be highly vulnerable as a consequence of their own medical conditions [24]. In this study, $25 \%$ cases had signs of dehydration among which 5\% were severely dehydrated, the majority of children having dehydration was found to be below 24 months of age $(80 \%)$, similarly, most of the children having history of fever were also below 24 months of age (77.8\%). Among the children who needed admission majority were below 24 months of age. $7 \%$ cases needed PICU care. No deaths were seen due to diarrhoea during the study period.

Rotavirus virtually infects all children by 3-5 years worldwide. Rotavirus mostly occurs between 6 to 23 months of age. Infants younger than 3 months of age are less likely to develop symptomatic illness, perhaps due to transfer of maternal antibody, breast feeding or age dependent physiology [25-27], while children above 5 years of age develop less severe gastroenteritis due to previous exposure that confers greater protection against subsequent disease [28]. In this study, majority of stool samples tested positive for rotavirus (66\%) followed by adenovirus (13\%). Most of the infected cases were below 24 months of age, which was similar to other studies. Bresee J et al in 2004 concluded in the first Report from the Asian Rotavirus Surveillance Network that $45 \%$ of acute diarrheal hospitalizations in children less than 5 years of age were due to rotavirus [29]. Study done among children in eastern Nepal showed rota antigen in $38.7 \%$ samples [11]. The large number of rotavirus positive cases detected in Dhulikhel hospital may also be due to the fact that the study was carried out during the winter months when we expect more numbers of rotavirus diarrhoea in the community.

In this study, majority of children were managed with ORS. IV fluids were needed in $26 \%$ cases. However, antibiotics were found to be used in $29 \%$ of children prior to presentation to the hospital, some of which were continued during the illness. Many developing countries struggle 
with huge disease burdens of diarrhoea where a wider approach to diarrhoea prevention may be required. Preventive strategies may be of relevance to both developed and developing countries [18]. Promotion of exclusive breastfeeding, improved complementary feeding practices, improved water and sanitary facilities and promotion of personal and domestic hygiene and rotavirus immunization must be reinforced. Subsequent development and testing of newer rotavirus vaccines have led to their introduction in most developed countries and approval by the WHO in 2009 for widespread use in developing countries. Emerging evidence indicates that the introduction of these vaccines is associated with a significant reduction in severe diarrhoea and associated mortality [18]. The immunization status for their age according to the EPI schedule in Nepal was completed in all the children $(100 \%)$ enrolled in this study which highlights the success of National Immunization Program in Nepal. During the study period our EPI schedule does not include rotavirus vaccine which is one of the major causes of acute diarrhoea in children. In this study rotavirus was detected in significant number of cases (66\%). An effective rotavirus vaccine would have a major effect on reducing diarrhoea mortality in developing countries like Nepal.

The main limitation of the study was its hospital based study, limited sample size and limited laboratory facilities. As the study was conducted in a tertiary care hospital mostly the severe cases or those who can afford were referred or brought to the hospital. Most of the simple cases of diarrhoea are treated locally at home or at the local health facility. The management of diarrhoea is getting better all over the country after implementation of IMCI training to all the health staffs in all over the country. Several different groups of viruses have been shown to be responsible for high incidence of acute viral gastroenteritis among children during their first few years of life. Rotavirus and adenovirus are the most important causes of early childhood gastroenteritis in both developed and developing countries, but concerning the limitation of our study other groups of viruses cannot be isolated and characterization of different organisms cannot be attempted due to lack of facilities. Seasonal variation of diarrheal cases could not be assessed due to specified time constraints of the study. These limitations have to be kept in mind when interpreting and discussing the results of the study.

\section{Conclusions}

Incidence of Acute diarrhoea was highest below 24 months of age. As the age increased the incidence decreased. Lack of safe drinking water, poor sanitation and poor living conditions are associated risk factors for childhood diarrhoea.

Exclusive breast feeding and good nutritional status decreases the incidence of diarrhoea. Viral diarrhoea is still the most common cause of childhood diarrhoea.

Rotavirus is the most common cause of acute gastroenteritis worldwide and vaccination will have a major impact on disease rates, morbidity, and mortality.

Most children are not dehydrated and can be managed using low osmolality ORS at home or in primary health care centres.

\section{Acknowledgements}

We would like to express sincere gratitude to all the faculty members of Department of Pediatrics, Dhulikhel Hospital, Kathmandu University Hospital for their continuous support and guidance for the study. We would like to acknowledge the support received from Medical University of Innsbruck, Austria, Department of Microbiology for providing the rotavirus and adenovirus detection ELISA kits used in the study.

Conflict of Interest: None declared

\section{References}

1. Control of Communicable Diseases Manual. Ministry of Health, Epidemiology and Disease Control Division 2003; 84-6.

2. Melo MC, Taddei JA, Diniz-Santos DR, May DS, Carneiro NB, Silva LR. Incidence of diarrhea: poor parental recall ability. Braz J Infect Dis. 2007; 11(6):571-9. http://dx.doi.org/10.1590/S141386702007000600009
3. Bern, C., Martines, J., deZoysa, I. and Glass, R.I . 1992. The magnitude of the global problem of diarrheal disease: a ten-year update. Bull WHO. 70:705-714.

4. Parashar UD, Gibson CJ, Bresee JS, Glass RI. Rotavirus and severe childhood diarrhea. Emerg Infect Dis 2006; 12:304-6. http://dx.doi.org/10.3201/eid1202. 050006
5. Greenwood D, Slack R.C.B. and Peutherer JF. Medical Microbiology A guide to microbial infections: Pathogenesis, immunity, laboratory diagnosis and control. 16th edition Churchill Livingstone 2002.

6. The impact of Water Supply and Sanitation interventions on child health: evidence from DHS surveys. Nepalese Demographic and Health Surveys (NDHS) 2006 
7. Bista, M.B. 2001. Infections Disease in Nepal. A collection of selected publications on communicable disease including vector borne disease. 1992-2000: 3-6.

8. CUKOR G., and BLACKLOW N. R., "Human Viral Gastroenteritis", Microbiological Reviews, Vol. 48 No 2, June 1984, pp. 157-179

9. SCHMITZ, H. et al. "Worldwide epidemiology in human Adenovirus infections", J. Epidemiology, Vol 117, pp.455-466

10. Nepal Millennium Development Goals. Progress Report 2010, United Nations Development Program Nepal 2012.

11. Shariff M, Deb M, Singh R. A study of diarrhoea among children in eastern Nepal with special reference to rotavirus. Indian J Med Microbiol [serial online] 2003 [cited 2013 Feb 12];21:87-90.

12. Selim Ahmed Severity of Rotavirus Diarrhea in Children: One Year Experience in a Children Hospital of Bangladesh Iran J Pediatr; Vol 19 (No 2); Jun 2009 Pages: 107116

13. RajKarnikar, A. 2000. Antibiotic resistant Vibrio cholerae isolated from Kathmandu valley and characterization of the isolates by biotyping and serotyping. A dissertation presented to Central Dept. of Microbiology.

14. Tanaka G, Faruque AS, Luby SP, et al. Deaths from rotavirus disease in Bangladeshi children: estimates from hospital-based surveillance. Pediatr Infect Dis J. 2007;26(11):1014-8. http://dx.doi.org/10.1097/INF.0b0 $13 \mathrm{e} 318125721 \mathrm{c}$

15. Paul SK, Kobayashi N, Nagashima $S$, et al. Phylogenetic analysis of rotaviruses with genotypes G1, G2, G9 and G12 in Bangladesh: evidence for a close relationship between rotaviruses from children and adults. Arch Virol. 2008; 153(11):1999-2012. http://dx.doi.org/10.1007/s00705008-0212-9

16. Khetawat D, Dutta P, Gupta S, et al. Emergence of rotavirus G4P8 strain among children suffering from watery diarrhea in Calcutta, India. Intervirology. 2001;44(5):306-10. http://dx.doi.org/10.1159/0000500 62

17. Glass RI, Lew JF, Gangarosa RE, et al. Estimates of morbidity and mortality rates for diarrheal diseases in American children. J Pediatr. 1991;118(4 pt 2): S27-S33. http://dx.doi.org/10.1016/S00223476(05)81422-2

18. Pickering LK, Synder JD. Gastroenteritis. In: Behrman RE, Kliegman RM, Jenson HB. Nelson Textbook of Pediatrics. 18th ed. Philadelphia PA: W.B. Saunders; 2008.

19. Final Draft unicef, www.unicef.org/specialsession/how.. ./edr_nepal_annex_en.doc

20. Family Health Survey 1996 Nepal: Family Health Survey. Department of Health Services, His Majesty's Government Kathmandu, Nepal.

21. Stanton, B. F. \& Clemens, J. D. 1987 Socioeconomic variables and rates of diarrhoeal disease in urban Bangladesh. Trans. R. Soc. Trop.

22. Ono, K., Rai, S. K., Chikahira, M., Fujimoto, T., Shibata, H., Wada, Y., Tsuji, H., Oda, Y., Rai, G., Matsumara, T., Hotta, H., Kawamura, T. \& Uga, S. 2001 Seasonal distribution of enteropathogens detected from diarrheal stool and water samples collected in Kathmandu, Nepal. SE Asian J. Trop. Med. Publ. Health 32(3), 520-526.

23. Lopez-de-Andres A, Jimenez-Garcia $R$, Carrasco-Garrido $P$, et al. Hospitalizations associated with rotavirus gastroenteritis in Spain, 2001- 2005. BMC Public Health 2008;8:109. http://dx.doi.org/10.1186/14712458-8-109

24. Lopman BA, Reacher MH, Vipond IB, et al. Epidemiology and cost of nosocomial gastroenteritis, Avon, England, 2002 2003. Emerging Infectious Diseases 2004;10:182734.

http://dx.doi.org/10.3201/eid1010. 030941

25. Rojas AM, Boher Y, Guntinas MJ, Perez Schael I. Homotypic immune response to primary infection with rotavirus serotype G1. J Virol. 1995;47:404-9.

http://dx.doi.org/10.1002/jmv. 1890 470418

26. Rimer HC, Wasserman SS, Flores J, Pichichero ME, Losonsky GA. Rotavirus-specifi c breast milk antibody in two populations and possible correlates of interference with rhesus rotavirus vaccine seroconversion. J Infec Dis. 1992;165:826-30.

http://dx.doi.org/10.1093/infdis/16 5.5 .826

27. Bass DM, Baylor M, Broome R, Greenberg HB. Molecular basis of age-dependent gastric inactivation of rhesus rotavirus in the mouse. J Clin Invest. 1992;89:1741-5. http://dx.doi.org/10.1172/JCI1157 76

28. Velazquez FR, Matson DO, Calva JJ, Guerrero L, Marrow AL, CarterCampbell L, et al. Rotavirus Infections in infants as protection against subsequent infections. $\mathrm{N}$ Engl J Med. 1996;335(14):1022-8. http://dx.doi.org/10.1056/NEJM19 9610033351404

29. Bresee J. Fang ZY, Wang B, Nelson EA, Tam J, Soenarto Y, et al. First Report from the Asian Rotavirus Surveillance Network. Emerg Infect DIs. 2004 Jun;10(6);988-95. http://dx.doi.org/10.3201/eid1006. 030519 